ISSN: 0213-2079 - ISSN electrónico: 2386-3889

DOI: https://doi.org/10.14201/shhmo2018402383405

\title{
EL SISTEMA DE SERVIDUMBRE EN ESTONIA: VISIÓN GENERAL E INFLUENCIA SUECA
}

\section{Serfdom System In Estonia: Overview And Swedish Influence}

\author{
David RAMIRO TROITIÑO
}

Tanel KERIKMÄE

Archil CHOCHIA

Universidad de Tecnología de Tallin (Estonia)

Correo-e: david.troitino@ttu.ee

RESUMEN: Este artículo está basado en una investigación sobre el sistema servil en Estonia y como la dominación sueca influyó en la vida cotidiana de los siervos estonios. La relevancia del tema viene dada por la peculiaridad del caso estonio que viene determinada por el carácter nacional del sistema ya que la masa campesina estaba compuesta casi exclusivamente por estonios, y por lo avanzado de las medidas suecas en materia social. El territorio que hoy configura Estonia fue ocupado durante siglos por distintos pueblos y potencias extranjeras, como los alemanes Bálticos, los daneses, los suecos, incluso por un breve periodo de tiempo los polacos, $\mathrm{y}$ finalmente los rusos. Aun hoy en día se hace referencia al periodo dorado, o los buenos tiempos suecos, para hablar de la ocupación sueca por lo que supuso para los derechos de la mayor parte de la población. La investigación revela ese carácter diferenciador y lo evidencia con diversas comparaciones temporales con otras partes de Europa.

Palabras clave: Servidumbre; Estonia; campesinos estonios; organización social; periodo sueco; reformas suecas.

ABSTRACT: This article is based on a research about the serfdom system in Estonia and how the Swedish domination influenced the daily life of the Estonian peasants. The relevance of this topic emanates from the Estonian 
DAVID RAMIRO TROITIÑO, TANEL KERIKMÄE Y ARCHIL CHOCHIA

EL SISTEMA DE SERVIDUMBRE EN ESTONIA: VISIÓN GENERAL E INFLUENCIA SUECA

peculiarity determined by the national essence of the system because the farmer frame was formed exclusively by national Estonians and because of the socially advance Swedish actions. The current territory of Estonia was occupied for several foreign people and powers, as the Baltic Germans, the Danish, Swedes, even for a short period Polish and Russians. Still currently the Swedish period is referred as the golden times, or the good Swedish time, because it has a positive print of the serf's lives. The research reveals these differences and exposes them with several temporal comparisons with other parts of Europe.

Key words: Serfdom; Estonia; Estonian peasants; social organization; Swedish period; Swedish reforms.

\section{INTRODUCCIÓN}

Estonia históricamente es identificada como la zona donde el denominado pueblo estonio se estableció paulatinamente tras siglos de lenta migración. Los estonios son un pueblo fino-ugrio muy probablemente originario de la zona europea de los Urales donde aún residen numerosos pueblos cuyas lenguas están emparentadas directamente con el estonio. Pausadamente emigraron hacia occidente en un movimiento poblacional del que no han quedado evidencias históricas más allá de ciertos hallazgos arqueológicos menores de difícil interpretación. La pujanza de los pueblos eslavos supuso una absorción social y cultural del crisol de culturas que habitaban en la amplia zona que incluía Europa del este y Asia y que actualmente está mayoritariamente ocupada por la Federación Rusa. La resistencia del pueblo estonio a la asimilación cultural los empujó hacia zonas más remotas al norte del continente y menos hospitalarias por sus duras condiciones climáticas. Una parte de este pueblo cruzó el mar Báltico y se estableció definitivamente en la actual Finlandia. La cercanía entre ambas naciones es obvia tanto en materia lingüística (ambas lenguas no pertenecen al grupo Indoeuropeo y sus similitudes son enormes), desarrollo histórico, económico y social ${ }^{1}$.

El pueblo Estonio estaba compuesto por diferentes tribus con una identidad común muy laxa que fue reforzada por la llegada de ocupantes extranjeros en busca de nuevas tierras y áreas de expansión. Pese a que Tácito menciona ya a

1. Singleton, Fred, y Upton, Anthony F: A short history of Finland. Londres, 1998.

Ediciones Universidad de Salamanca / అ@@ Stud. his., H. ${ }^{a}$ mod., 40, n. 2 (2018), pp. 383-405 
DAVID RAMIRO TROITIÑO, TANEL KERIKMÄE Y ARCHIL CHOCHIA

EL SISTEMA DE SERVIDUMBRE EN ESTONIA: VISIÓN GENERAL E INFLUENCIA SUECA

los pueblos Aesti en su obra Germania en el año 98, no es hasta que en el siglo séptimo cuando los vikingos de Gotland viajan a las islas occidentales, que Estonia entra plenamente en la época histórica. A partir de ese momento las fuentes son numerosas y hacen referencia constante a los intentos de ocupación por parte de daneses, suecos, eslavos de los principados de Pskov y Kiev, lituanos y alemanes bálticos de la orden de los Hermanos de la Espada de Livonia ${ }^{2}$ (Subsidiaria de los caballeros Teutones que exterminaron al pueblo Prusiano también en la zona báltica).

La situación geográfica de Estonia, rodeada por civilizaciones poderosas desde el punto de vista militar, económico, cultural y social, convirtió el país en un área de conflicto constante y deseo de ocupación. La religión fue la fuerza conductora del esfuerzo colonizador, especialmente el cristianismo desde que en 1193 el Papa Celestino III propugnara una cruzada contra los paganos del norte de Europa. La conversión de los reductos de paganos europeos proporcionó la justificación moral para la expansión de germanos y escandinavos por el este y norte de Europa, pero también sirvió como canalizador de la organización social y económica de los nuevos territorios a través de las propiedades eclesiásticas, especialmente monasterios, y la organización de la iglesia a través de obispados, y parroquias, que vertebraba de manera efectiva la mayor parte del territorio, especialmente el medio rural. La inexistencia de núcleos urbanos estonios estables más allá de fortificaciones muy básicas y de ciudades habitadas por extranjeros, como Tallin ${ }^{3}$, fundada por los daneses, daba un carácter eminentemente rústico a la población estonia.

Los ocupantes desarrollaron un sistema de explotación económica basado en la religión en cierta manera similar al de las encomiendas españolas en la conquista de América. La población local una vez bautizada, en general de manera forzada, pasaba a depender bajo un régimen feudal de su mentor espiritual. Estos beneficios llevaron a situaciones surrealistas, pero comunes, como la conversión al cristianismo de estonios por parte de los daneses y la posterior anulación de dicha liturgia por parte de los alemanes Bálticos para volver a bautizarlos de acorde a sus intereses y así dominar legalmente a esos individuos. Este tipo de conversiones condujo a un adoctrinamiento religioso muy básico entre la población local que en la mayoría de los casos oficialmente se había convertido al cristianismo pero que en la realidad seguían con sus ancestrales practicas animistas. Esta situación se extendió en el tiempo hasta la llegada de los suecos al norte de Estonia, que a través de la implementación de un sistema

2. Laur, Mati: History of Estonia. Tallin, 2000.

3. Tallinn (en idioma estonio) procede de Tani Linn, o ciudad de los daneses. 
de educación organizado y efectivo a manos de la iglesia sueca, llegó realmente a la mayor parte de la población estonia ${ }^{4}$.

Otras zonas Bálticas bajo esta influencia colonizadora religiosa como Prusia, sufrieron un proceso diferente ya que la población local fue totalmente exterminada o asimilada a la cultura germánica y numerosos colonos procedentes de Alemania se asentaron en las áreas rurales, no solamente en los núcleos urbanos.

Este panorama estonio dibujó la creación de una élite económica urbana dedicada al comercio (Las ciudades estonias pertenecían a la Liga Hanseática), una aristocracia rural propietaria de latifundios (basada en aspectos culturales como elemento diferenciador) y la gran masa campesina sometida, eminentemente estonia que tenía restringido el acceso a los núcleos urbanos y dependía enormemente de la voluntad casi omnipotente de la nobleza.

Durante los siglos posteriores a la expansión occidental en la zona Báltica se asentó definitivamente un modelo económico basado en las grandes propiedades rurales trabajadas por campesinos estonios bajo la dirección de la aristocracia, eminentemente germana, que enviaba sus excedentes a las ciudades que comerciaban con el resto de Europa, principalmente con puertos pertenecientes a la Liga Hanseática. Durante siglos las mayores exportaciones de Estonia fueron trigo, madera, pieles, y otros productos primarios, y su principal destino, la actual Alemania.

El asentamiento de la élite germana a nivel social no significó el fin de las guerras en territorio estonio, todavía durante siglos campo de batalla entre distintas civilizaciones, pero el cambio nominal de la cabeza del estado, dependiendo del vencedor de cada contienda, no significaba grandes cambios a nivel local. La cabeza del estado podía cambiar de Livonia a Rusia o a Suecia, pero la composición social interna era prácticamente la misma en todas las ocasiones, aristocracia germana, comerciantes germanos y campesinos estonios. La cercanía de Livonia (actualmente Letonia y parte del sur de Estonia) con su radiante y dinámica capital Riga, supuso una influencia determinante para el triunfo germano a nivel aristocrático, creando un sistema permeable que aceptaba nuevas incorporaciones en su más alto nivel, como nobles Suecos o Daneses, o gobernadores rusos, como el famoso poeta Pushkin, pero que a medio plazo los asimilaba culturalmente al ámbito germano y que se desemparejaba de la gran masa poblacional gracias a las diferencias nacionales que en la época todavía se

4. Runciman, Steven: The Crusades and the Military Orders: expanding the frontiers of medieval Latin Christianity. Tallin, 2001, pp. 74 y ss. 
DAVID RAMIRO TROITIÑO, TANEL KERIKMÄE Y ARCHIL CHOCHIA

EL SISTEMA DE SERVIDUMBRE EN ESTONIA: VISIÓN GENERAL E INFLUENCIA SUECA

consideraban raciales también. Por tanto, un sistema relativamente poroso en su más alto nivel pero estanco en la base de la pirámide social ${ }^{5}$.

El comienzo de la edad moderna en Estonia supuso un tiempo aún más convulso con la ocupación del sur de Estonia brevemente por parte de PoloniaLituania, para su posterior vuelta al dominio de Livonia, y posteriormente a la dominación sueca. La Gran Guerra del Norte (1700-1721) supuso una devastación considerable y la incorporación de Estonia al imperio ruso ${ }^{6}$. El desarrollo de gran parte de la guerra en suelo estonio tuvo unas consecuencias nefastas para la población debido a los continuos saqueos, hambrunas y epidemias, superviviendo únicamente alrededor de 120000 personas en el territorio de estonia lo que influyó de manera notoria el desarrollo del sistema de social imperante en el medio rural.

\section{LA ORGANIZACION MEDIEVAL DE ESTONIA}

El nuevo régimen feudal tardo mucho en implementarse en Estonia debido a las continuas guerras y a la inestabilidad social. El sistema comenzó con la creación y recaudación de impuestos a principios del siglo XII. Hay fuentes que revelan diversos impuestos de carácter eclesiástico que probablemente fueron los primeros en ser establecidos. También hay fuentes que hacen referencia a un impuesto a pagar en grano por los siervos a los terratenientes. Aunque es difícil estimar la capacidad recaudadora de la nobleza, que en su mayor parte aun residía en las ciudades danesas y alemanas, desplazándose a sus posesiones solamente para cobrar los impuestos, lo cual genera una imagen de gran autonomía servil e independencia mientras cumplieran con sus obligaciones recaudatorias. Esta situación cambió en el siglo XIV con la construcción de casas señoriales en las propiedades rurales de la nobleza en forma de fortalezas y casonas, lo que revela una mayor presencia de la aristocracia en el medio rural ${ }^{7}$.

El periodo medieval es más conocido en el norte de Estonia, bajo la ocupación danesa, ya que los sacerdotes daneses compusieron un censo que incluía propiedades y vasallos en $1240 .{ }^{8}$ De acuerdo con este censo, solamente el $4 \%$

5. Anatol Lieven: The Baltic revolution: Estonia, Latvia, Lithuania and the path to independence. London, 1994, pp.84-97.

6. Karonen, Petri: «Coping with Peace after a Debacle: the Crisis of the Transition to Peace in Sweden after the Great Northern War (1700-1721).» Scandinavian Journal of History 33.3, 2008, pp. 203-225.

7. Sillaste, Kyllike: «Conquest and survival: An outline of Estonian history.» World Affairs, 157.3, 1995, pp. 119-123.

8. Liber Census Daniae 
DAVID RAMIRO TROITIÑO, TANEL KERIKMÄE Y ARCHIL CHOCHIA

EL SISTEMA DE SERVIDUMBRE EN ESTONIA: VISIÓN GENERAL E INFLUENCIA SUECA

de la nobleza del norte de Estonia provenía de los descendientes de la anterior aristocracia local, y el resto estaba formada por alemanes y daneses.

La situación del campesinado no sufrió cambios sustanciales con la llegada de daneses y germanos, que sustituyeron a la nobleza local en la obtención de impuestos y servicios por parte de los campesinos. Aunque no hay evidencias de que se restringiera el acceso a propiedad de la tierra por parte del campesinado.

En las zonas de influencia germánica se desarrolló una red de castillos y fortalezas por parte de la orden militar de monjes guerreros Teutones con el objetivo de controlar a la población local, eliminar el paganismo, hacer más efectiva la recaudación de impuestos y protegerse de amenazas externas, de la expansión de los principados rusos de Pskov, Novorogod y Kiev. El territorio fue dividido en unidades administrativas que dependían de un castillo con un mayordomo perteneciente a la orden a cargo de todos los asuntos militares, económicos y sociales. En términos religiosos la cohesión al nuevo territorio fue articulada a través de los conventos de la orden militar, cuyos miembros, a imitación de lo que sucedía en tierra santa, estaban obligados a residir en monasterios para mantener su carácter de monjes guerreros. Por tanto se estableció una forma de propiedad corporativa donde la orden era la propietaria y sus miembros gestionaban los distintos activos de manera individual ${ }^{9}$.

En la zona de influencia danesa, en el norte del país, la propiedad fue eminentemente privada, siendo los mayores terratenientes la corona danesa y los obispos, donde dado su carácter público los siervos locales tenían una gran autonomía.

A mediados del siglo XII se potenció la llegada de colonos occidentales a Estonia ya que la densidad de población era muy baja, pero el plan no tuvo mucho éxito debido a las duras condiciones climáticas, al peligro constante de guerra y caos en la zona y la baja probabilidad de desarrollar un sistema social de campesinado libre debido a las amenazas constantes de una nobleza beligerante. De todas formas, las principales islas estonias y la costa noreste fueron colonizadas por campesinos provenientes de Suecia, creando numerosos pueblos en los cuales los campesinos eran propietarios de la tierra y sus obligaciones ante la nobleza se limitaban al pago de impuestos. La población sueca en esta parte de Estonia se mantuvo hasta 1944, cuando la Unión Soviética se anexionó Estonia y la población de origen sueco emigró masivamente a Suecia ${ }^{10}$.

9. Mol, Johannes A., Klaus Militzer, and Helen J. Nicholson, eds: The Military Orders and the Reformation: Choices, State Building, and the Weight of Tradition. Hilversum, 2006, pp.194-201.

10. de la Guardia, Ricardo M. Martín, y Guillermo A. Pérez Sánchez, eds: Los paises de la antigua Europa del Este y España ante la ampliación de la Unión Europea. Valladolid, 2001, pp. 98 y ss.

Ediciones Universidad de Salamanca / అ@@ Stud. his., H. ${ }^{a}$ mod., 40, n. 2 (2018), pp. 383-405 
DAVID RAMIRO TROITIÑO, TANEL KERIKMÄE Y ARCHIL CHOCHIA

Los siglos XIII y XIV fueron escenario de conflictos entre las autoridades civiles y religiosas por el control de la tierra y los campesinos. Es un periodo en cierta manera oscuro donde las distinciones sociales quedan marcadas y la participación en la vida pública de la población local desaparece completamente. Pese a lo cual el sistema de servidumbre seguía basado principalmente en una dependencia legal y el pago de impuestos de los siervos. No es hasta el siglo XV cuando el sistema servil se implementa en Estonia de manera efectiva, con la introducción de leyes para evitar que los siervos escaparan de los latifundios y garantizando su devolución en caso de apresamiento. Este tipo de leyes refleja una situación en la cual lo siervos se movían libremente entre distintas zonas con el consiguiente perjuicio económico para la nobleza, que intentó evitar dicha libertad con leyes coercitivas. También hay registros del siglo XV de transacciones económicas de compra venta de siervos, tanto con tierra como sin ella, dato este último revelador del concepto de mercancía que la nobleza estaba desarrollando sobre sus siervos.

De todas formas, todavía seguía existiendo diferentes estratos entre los siervos, una parte considerable, que trabajaba tierras de la Orden o de la corona, podía considerarse autónoma ya que sus obligaciones no pasaban más allá del pago de impuestos. A su vez todavía existían campesinos libres ${ }^{11}$ que poseían la tierra y su única obligación ante las autoridades era el pago de impuestos en especie o en moneda, para eximirse de la prestación de servicios u obligaciones.

La tendencia hacia la servidumbre se aceleró a finales de siglo, y ya a principios del siglo XVI la mayoría de los campesinos estonios se habían convertido en siervos. Como vía de escape, al igual que sucedía en otros lugares de Europa, las ciudades se convirtieron en focos de libertad al negarse a devolver a los siervos prófugos a sus dueños legales. Las ciudades estonias tenían un índice de natalidad negativa y necesitaban mano de obra para sus actividades comerciales, por lo que los fugitivos eran bienvenidos pero no aceptados como ciudadanos. Durante el siglo XIV la mayoría de la población urbana era germana, aunque poco a poco la población estonia crecía en las ciudades, incorporándose a la vida ciudadana ${ }^{12}$. El siglo XV, además de significar un empeoramiento de las condiciones rurales, también significó la restricción de la ciudadanía exclusivamente para aquellos que pudieran pagar el impuesto ciudadano, perjudicando enormemente a las clases sociales menos afortunadas, los estonios, privándoles así de los

11. La situación de los campesinos-colonos suecos fue extraordinaria en relación con el desarrollo del servilismo en Estonia ya que siempre conservaron su independencia jurídica.

12. Kerikmäe, Tanel: Estonia in the European legal system: protection of the rule of law through constitutional dialogue. Tallin, 2009, pp.43-47.

Ediciones Universidad de Salamanca / @®@@ Stud. his., H. ${ }^{a}$ mod., 40, n. 2 (2018), pp. 383-405 
DAVID RAMIRO TROITIÑO, TANEL KERIKMÄE Y ARCHIL CHOCHIA

EL SISTEMA DE SERVIDUMBRE EN ESTONIA: VISIÓN GENERAL E INFLUENCIA SUECA

derechos inherentes a la ciudadanía y relegándoles aún más en la escala social.

Finalmente, el triunfo de la reforma en el norte de Europa significó el fin de la mayoría de las posesiones eclesiásticas en Estonia, que incluía extensas propiedades de la Orden de Livonia. La aristocracia se convirtió rápidamente al protestantismo y privatizo los latifundios, endureciendo así la vida de los siervos que generalmente habían tenido mucha más autonomía bajo el control eclesiástico, y sometiéndoles a un régimen de servidumbre mucho más estricto.

\section{EL PERIODO SUECO O EL PERIODO DORADO}

Tras la victoria sueca en la guerra de Livonia y el tratado de paz firmado con Rusia en 1583, el norte de Estonia estuvo bajo el dominio escandinavo al igual que una considerable parte de Finlandia. En un principio la dominación sueca no tuvo un importante impacto social en la población rural ya que los nobles se sometieron a la nueva autoridad bajo la condición de mantener intactos sus privilegios. El acuerdo fue respetado por la corona sueca por lo que la estabilidad social fue una constante durante el inicio del periodo sueco.

La organización política estaba basada en la participación de la nobleza en los asuntos de estado a través de la asamblea general de Estonia que se reunía cada tres años y estaba formada por la nobleza del país y la corona sueca, representada por el gobernador. Las propiedades de la corona estaban formadas principalmente por parte de las antiguas propiedades de la Orden de Livonia, propiedades monacales y religiosas y latifundios privados abandonados en la guerra. La administración sueca puso estas tierras bajo el control de un representante real que actuaba como administrador, además de donar generosamente parte de las tierras adquiridas entre la nobleza sueca y local para asegurarse su lealtad y el control del territorio. A finales del siglo XVI la mayor parte de la tierra de Estonia estaba en manos privadas, bajo el control mayoritario de la nobleza Germano-Báltica, que posteriormente rechazó enérgicamente cualquier tipo de reforma que redujera su base de poder, el control del medio agrario a través de extensos latifundios y el control de la población a través del sistema de servidumbre.

El sur de Estonia, temporalmente ocupado por fuerzas polacas, finalmente cedió ante el empuje sueco y se incorporó a sus posesiones en 1629. La ocupación allí generó un movimiento de resistencia entre la nobleza local mucho mayor que en el norte, por lo que sus derechos y privilegios no fueron respetados en un grado tan alto y la presencia del gobierno sueco fue más fuerte, algo que notaron especialmente los siervos. Finalmente la isla de Saaremaa, en manos danesas, pasó a la soberanía sueca a través del tratado de paz de Brömsebro en

Ediciones Universidad de Salamanca / @®@@ Stud. his., H. ${ }^{a}$ mod., 40, n. 2 (2018), pp. 383-405 
1645, englobando así toda Estonia bajo el poder del Rey Gustavo Adolfo II de Suecia ${ }^{13}$.

El control del estado central se potenció a través de una presencia mayor de la iglesia sueca en la vida diaria de Estonia ${ }^{14}$. La principal novedad vino de la creación de visitantes religiosos que debían controlar todas las parroquias del país, las creencias de los siervos y la lealtad de las congregaciones. La vida intelectual también se potenció y controló de manera estricta, fundándose por este Rey diversos colegios, aún en funcionamiento, y la Universidad de Tartu, la más antigua y prestigiosa de la zona. Así pues, el control del estado se volvió más efectivo a través de la educación y de la participación de la iglesia sueca en la vida cotidiana de los feligreses.

De todas formas, a la muerte del Rey Gustavo Adolfo II sus sucesores cedieron más tierras a la aristocracia sueca que lentamente se estaba asimilando a la aristocracia germano Báltica de la anterior Livonia y que finalmente fue incorporada a los organismos de gobierno como la Asamblea General, pero que no estaba presente en las Asambleas de la metrópoli, verdaderas fuentes de gobierno, acentuando así aún más su carácter local y diferenciado. La pérdida de control de los latifundios públicos y las constantes guerras redujeron el poder del Rey en el territorio, aumentando así el poder de la aristocracia y por tanto incrementando sus privilegios y dominación y explotación sobre el campesinado.

En la segunda mitad del siglo XVII había en Estonia unos 1000 latifundios pertenecientes a la corona, la nobleza, las ciudades y la iglesia que producían principalmente grano para su exportación a Europa occidental y Suecia, llegándose a conocer a Estonia cómo la cesta el pan sueco. El funcionamiento de los latifundios dependía enormemente de la corvea, donde las distintas granjas incluidas en las grandes extensiones señoriales estaban obligadas a proporcionar trabajo y animales de manera gratuita. Además los siervos estaban obligados a proporcionar una parte de lo producido en sus granjas al señor sin ninguna remuneración. La expansión agraria del siglo XVIII significó una extensión de los latifundios y mayores necesidades de trabajo humano, lo que empeoró la situación de los campesinos que vieron incrementadas sus obligaciones sin por ello obtener rédito ninguno. Esta situación aceleró el éxodo rural hacia los centros urbanos con la esperanza de tener unas mejores condiciones vitales, a

13. Evas, Tatjana: et al. «General Frameworks.» The Law of the Baltic States. Berlín, 2017. $3-40$.

14. Pérez, Juan Carlos Monroy, and David Ramiro Troitiño: «El idioma estonio y la influencia geopolítica sobre su desarrollo.» Onomázein 33, 2016, pp. 189-200.

Ediciones Universidad de Salamanca / 요 Stud. his., H. ${ }^{a}$ mod., 40, n. 2 (2018), pp. 383-405 
lo que la aristocracia respondió con medidas legislativas, como la ley de Policía Rural de 1671, que facilitaba el retorno de los fugados a sus anteriores propietarios. También se aprobaron leyes refrendando la propiedad señorial de los hijos de los siervos, incrementando aún más la presión sobre el campesinado. Esta época de finales del XVII igualmente es rica en fuentes relacionadas con la compra-venta de siervos sin que estuvieran unidos a la tierra, un signo evidente de su completa dominación y explotación por parte de la nobleza.

El modelo de servidumbre seguía, en líneas generales, el modelo germano de servidumbre implantado al este del río Elba. En un principio, el territorio al este de éste río estaba menos poblado, por lo que para atraer colonos las condiciones que se ofrecían eran mejores que en la zona occidental de Alemania, con menos días de trabajo en la tierra del noble, menos impuestos y más facilidades para el arrendamiento de la tierra. Pese a que a Estonia no llegaron colonos campesinos de Alemania en un número significativo por razones ya explicadas, la baja densidad de población indujo a la nobleza a seguir el modelo común a la línea del este del Elba. Cada latifundio tenía en realidad su propio sistema de servidumbre, y la costumbre y tradición tenían mucho que ver en ello, pero aun así había unas condiciones en mayor medida comunes que en general eran más duras que en occidente ${ }^{15}$.

En los latifundios de Estonia todavía se conservó el carácter hereditario de los siervos hasta finales del sistema servil cuando ya no existía en el occidente europeo, el pago pecuniario y en especie por el arrendamiento de la tierra era en un principio menor en el este del rio Elba, pero se incrementó cuando la escasez de mano de obra agraria dejó de ser un problema. El pago en trabajo, la corvea, por el arrendamiento de la tierra tuvo una evolución similar, en un principio se limitaba a quizás unos días al año, menos que en occidente, pero a finales del XVIII se había convertido en algunos casos en cinco días semanales, y en el caso de los siervos sin tierra a tiempo completo ${ }^{16}$. En definitiva, la mayor diferencia entre el sistema servil germano, imperante en Estonia bajo sus peculiaridades locales, fue la evolución del occidente alemán donde el dinero se convirtió en el mayor bien y la mayoría de las obligaciones de los siervos se podían canjear por aportaciones monetarias, y la situación en Estonia donde el producto agrario y los siervos seguían siendo el patrón de riqueza imperante.

15. Kerikmäe, Tanel, y Archil Chochia, eds: Political and Legal Perspectives of the EU Eastern Partnership Policy. Berlin, 2016, 211-220.

16. Olsson, Mats: «Manorial economy and corvée labour in southern Sweden 1650-1850.» The economic history review 59.3, 2006, pp. 481-497.

Ediciones Universidad de Salamanca / @®@@ Stud. his., H. ${ }^{a}$ mod., 40, n. 2 (2018), pp. 383-405 
DAVID RAMIRO TROITIÑO, TANEL KERIKMÄE Y ARCHIL CHOCHIA

EL SISTEMA DE SERVIDUMBRE EN ESTONIA: VISIÓN GENERAL E INFLUENCIA SUECA

Ante la situación de continua degradación de la situación de los siervos, el Rey Carlos XI de Suecia inició numerosas reformas que influenciarían enormemente la vida de los campesinos en la Estonia sueca, diferenciando a los siervos estonios del resto de la zona de influencia germana, pero sin asimilarlos a los siervos suecos. Bajo su reinado (1672-1697) se produjo un proceso de saneamiento de las cuentas públicas a través de la expropiación parcial de los latifundios de la nobleza, o reducción de las propiedades, para así incrementar los ingresos del estado. Lo que unido al desarrollo de un modelo de gobierno absolutista incrementó enormemente la influencia del estado central en la sociedad sueca y en sus posesiones Bálticas, pero que generó numerosos conflictos con las aristocracia local. La llamada Gran Reducción aprobada por el parlamento sueco ${ }^{17}$ en 1680 que afectaba a aquellos latifundios que desde el dominio sueco habían pasado de públicos a privados fue el detonante del malestar de la nobleza en Estonia. El antiguo sistema de gobierno conjunto avalado por la Asamblea General que representaba a la nobleza y a la corona había desaparecido, aunque finalmente el proceso se desarrolló de manera pacífica $^{18}$. El aumento de la tierra de la corona incrementó la influencia de las decisiones del Rey Sueco entre los siervos estonios ya que la aplicación de su legislación tenía un efecto directo, pese a que los arrendatarios de tierra pública tuvieran una autonomía muy grande en su relación con los siervos vinculados con esas fincas.

El proceso reformador no paró ahí, y en pocos años se introdujeron numerosas novedades que afectaron sobremanera a los campesinos y al sistema servil:

- Los latifundistas y propietarios de tierras perdieron el derecho de castigar físicamente a sus siervos

- Se prohibió la venta de siervos sin tierra. Manteniéndose aún la posibilidad de vender la tierra con todo su contenido, incluyendo los animales, edificios y siervos.

- Se prohibió el traslado de siervos de una propiedad a otra.

- Se aceptó la propiedad privada de los siervos. Antes de esta reforma todo objeto de los siervos pertenecía a su señor feudal.

- Se prohibió la usurpación de la tierra del campesinado libre por parte de la nobleza.

17. El parlamento sueco no contaba con representación de la nobleza de estonia.

18. Braghiroli, Stefano, y Carta, Catalina: «An index of friendliness toward Russia: An analysis of the member states and Member of the European Parliament's positions.» PanEuropean Institute Electronic Publication of 15.09 (2009).

Ediciones Universidad de Salamanca / 요 Stud. his., H. ${ }^{a}$ mod., 40, n. 2 (2018), pp. 383-405 
La reforma sueca mejoró ostensiblemente las condiciones de vida de los siervos estonios, especialmente de aquellos pertenecientes a latifundios reales, que obtuvieron aún más prerrogativas, pero de ninguna manera se puede equiparar con la abolición de la servidumbre en Suecia durante el mismo periodo y la creación de una masa de campesinos libres ${ }^{19}$. También fue remarcable la mejoría de los siervos en los latifundios eclesiásticos, ya que la iglesia implementó la reforma del rey de manera rápida y eficiente. A nivel privado, la aristocracia local no llegó realmente nunca a implementar una reforma que socavaba su autoridad y bienestar económico.

La reforma tuvo un alcance limitado porque numerosas tierras expropiadas fueran arrendadas a sus anteriores propietarios, por lo que la situación no cambio mucho para los siervos de las mismas. Empeorando en algunos casos su situación ya que la nobleza necesitaba pagar la renta real y explotaba aún más a los siervos para obtener un redito económico mayor.

Pero también hubo nuevos arrendatarios que alquilaron posesiones reales, como artesanos ricos, comerciantes pudientes y algunos campesinos libres, que se interesaron en este modelo de alquiler por ser la renta relativamente baja y poder ser pagada parcialmente en grano y parcialmente en dinero, lo que facilitaba el cumplimiento de los plazos.

La prematura muerte del Rey, el acceso al trono de su hijo Carlos XII in 1698 y el estallido de la Gran Guerra del Norte (1700-1721) supuso un caos social en el área del que se benefició la nobleza local. El imperio Ruso se afianzó en la zona gracias a una política similar a la del principio del periodo sueco, acuerdos con la aristocracia local respetando sus privilegios e independencia. Así, tras la caída de Tallinn en 1710 el resto de Estonia capituló rápidamente con unas condiciones muy favorables. El Zar Pedro I devolvió a la nobleza germana local las tierras confiscadas por la corona sueca, privatizando así de nuevo la gran mayoría de la propiedad de la tierra, lo que en la práctica significó un retroceso de las reformas suecas, la abolición del proceso de emancipación servil y un serio empeoramiento de las condiciones de los siervos.

De todas formas, la reforma sueca vino sucedida por la Gran Guerra del Norte y una importante plaga que diezmó la población, por lo que sus efectos beneficiosos probablemente nunca llegaran a ser apreciados por los siervos, preocupados por su propia supervivencia.

19. Vernygora, Vlad. «Discovering the Baltics? Think Tallinn! Perspectives for New Zealand in the Baltic States.» Tallin, 2011, pp.32-33.

Ediciones Universidad de Salamanca / 요 Stud. his., H. ${ }^{a}$ mod., 40, n. 2 (2018), pp. 383-405 
DAVID RAMIRO TROITIÑO, TANEL KERIKMÄE Y ARCHIL CHOCHIA

EL SISTEMA DE SERVIDUMBRE EN ESTONIA: VISIÓN GENERAL E INFLUENCIA SUECA

\section{LA INFLUENCIA SUECA EN LA VIDA DIARIA DE LOS SIERVOS ESTONIOS}

El periodo de dominación sueca de Estonia coincidió en el tiempo con la creación del estado moderno y la expansión de su influencia sobre todos los súbditos. Un proceso complejo ya que al mismo tiempo la nobleza expandía sus poderes feudales chocando de manera agresiva ambas tendencias. En general el periodo sueco socavó el poder de la nobleza en Estonia como intermediario en las relaciones de la corona con la mayor parte de sus súbditos formada por siervos rurales. Ya en el primer año de dominación sueca el poder absoluto de la nobleza sobre sus siervos fue abolido a través del privilegio de Augusto Segismundo en 1561 en su artículo 2620. El Rey Sueco Erik XIV (reinado de 1560-1568) presionó a la nobleza local de Estonia para establecer vínculos directos entre la corona y los siervos, como también expresó públicamente el príncipe Carlos en una reunión con la nobleza local en $1601^{21}$. El proceso fue continuado por el Rey Gustavo Adolfo II quien presentó en 1626 una reforma del sistema judicial para incrementar el peso de la corona en los asuntos legales y así incrementar la influencia real en la relación entre siervos y nobles ${ }^{22}$.

En el mismo sentido, en 1632 se presentó una reforma judicial en la cual se limitaba el poder de la nobleza sobre los siervos al incluir dentro de la jurisdicción de los tribunales comarcales todos los asuntos criminales relacionados con los siervos. Las victimas de acciones criminales podían acudir directamente a los tribunales reales en busca de justicia, saltándose la anterior omnipresente justicia local en manos del terrateniente. Por ejemplo, cuando en 1672, un siervo fue letalmente herido en las tierras de Rasik durante una reyerta entre campesinos, el gobernador provincial influyó para que el caso fuera directamente a los tribunales comarcales ${ }^{23}$.

La reforma judicial instaurada por Suecia tuvo también un impacto considerable entre la población, ya que establecía un vínculo directo entre los súbditos y el monarca, entre los siervos y la cabeza del estado. La nueva situación creó enormes expectativas entre los siervos, que veían la intervención real como

20. Archivo local de Virve. Folvark, pan i poddannyj. Agrarnye otnosheniya v polskikh vladeniyakh na territorii Juzhnoi Estonii vkontse XVI-nachale XVII veka, 199-133, ä. 58ü, 1561.

21. Archivos Históricos de Estonia. TARTU (EHA), 1601-6-2937.

22. Archivo Historico del EELK. Kirjavahetus Bielefeld-Stieghorsti Gustav Adolfi kogudusele kuulunud oreli vahendamisest Avinurme kogudusele.

23. Archivos Históricos de Estonia. TARTU (EHA), 861-1-3390, 'Inquisitio wegen eines übel verwundeten Baurens Ebarte Mickß und eines auff Rasick im Gefangnuß gestorbenen frey Kerlß Bents', 1672. 
DAVID RAMIRO TROITIÑO, TANEL KERIKMÄE Y ARCHIL CHOCHIA

EL SISTEMA DE SERVIDUMBRE EN ESTONIA: VISIÓN GENERAL E INFLUENCIA SUECA

un freno a las decisiones arbitrarias y absolutas de la nobleza. Por ejemplo, los campesinos de Karkus, exhortaron directamente al gobernador sueco de Estonia a través de una misiva conservada en los registros parroquiales con palabras sobre justicia y protección de los más débiles frente a las afrentas de los poderosos ${ }^{24}$.

Pese a estas reformas, la influencia del estado en la vida rural estaba limitada a ciertos ámbitos, y en muchos casos a las posesiones eclesiásticas y de la corona, ya que la nobleza no participó en las reformas de manera positiva ya que las veían como una amenaza a su estatus social. De todas maneras, uno de los campos donde la influencia sueca se hizo sentir de forma más directa en la vida de los siervos de Estonia fue en lo referente a los impuestos y el sistema de corvea real. La dominación sueca trajo consigo la introducción de impuestos reales que fluían directamente de los siervos a la corona. Pese a que la gestión de los impuestos en su vertiente más práctica dependía de los señores feudales (recaudación y envío) el estado consideraba a los siervos como pagadores de impuestos ${ }^{25}$. Los trabajos de los siervos para el estado ampliaron el sistema de Corvea, que anteriormente era un monopolio del terrateniente, pero que en la época sueca incluyó al estado como beneficiario del trabajo campesino. Evidentemente el estado como latifundista y propietario de grandes extensiones de terreno también recibía las tradicionales contraprestaciones en trabajo de los siervos. Pero la introducción de un sistema de trabajo estatal incluía a todos los siervos de Estonia, creando así otro vínculo entre el Estado y los siervos saltándose la intermediación de la nobleza. La mano de obra servil a nivel estatal fue usada principalmente en el desarrollo de fortificaciones y preparativos militares. Obviamente la nobleza en un principio se negó rotundamente a tal interferencia del estado en lo que consideraban sus asuntos locales, pero finalmente fue forzada a aceptar un sistema de cuotas y la aceptación de la prioridad de las necesidades militares del Reino sobre su relación con sus siervos ${ }^{26}$.

Las necesidades bélicas de la monarquía Sueca impusieron nuevos usos en relación a los siervos y el servicio militar. Si anteriormente la responsabilidad militar recaía en la nobleza, Suecia creó un vínculo directo entre el estado y los siervos. El príncipe Carlos en 1600 consideraba que se necesitaban reclutas locales de extracto servil para la lucha contra Polonia. En 1605 el ya Rey Carlos IX

24. Archivos Históricos de Estonia. TARTU (EHA), 1-1-112, ff. 44-45v, Hulpar Hanß and Putnik Martt al gobernador de Estonia Bengt Horn, 22 Febr. 1672.

25. Archivo histórico de LSHA, 7363-5-28, p. 5, 'Ordnung, wonach die pauren alhie in Liefland sollen stazei geben', 12 Sept. 1622.

26. Archivo Histórico de la ciudad de Tallin, Actio Appellatoria in causa Claus Habben und Christoph Brehmers, 1686-1687. TLA.230.3.879

Ediciones Universidad de Salamanca / @®@@ Stud. his., H. ${ }^{a}$ mod., 40, n. 2 (2018), pp. 383-405 
DAVID RAMIRO TROITIÑO, TANEL KERIKMÄE Y ARCHIL CHOCHIA

EL SISTEMA DE SERVIDUMBRE EN ESTONIA: VISIÓN GENERAL E INFLUENCIA SUECA

ordenó una leva de varios centenares de siervos tanto de latifundios estatales como de la nobleza. Estos siervos tras su servicio fueron liberados de sus obligaciones serviles y obtuvieron tierra libre de cargas fiscales, convirtiéndose en campesinos libres ${ }^{27}$.

Con el estallido de la guerra entre Suecia y el Imperio Ruso en 1656, se promulgó un edicto en 1657 por el cual se conminaba a los nobles y siervos (ambos) a incorporarse en las unidades territoriales de defensa o en los cuerpos de la milicia local guarneciendo las fortificaciones del Reino. Es relevante que el edicto ponga de manifiesto de manera específica que la nobleza no podía impedir la incorporación de sus siervos al ejército real con la excusa de ser necesario su trabajo en el latifundio ${ }^{28}$. Este hecho es fundamental en el proceso de vinculación servil con la corona ya que rompía claramente la sujeción exclusiva de los siervos a la nobleza y su intermediación todopoderosa. De todas formas, la respuesta de los siervos fue tibia ya que no hay que olvidar que los peligros de la guerra con frecuencia significaban grandes privaciones y altas posibilidades de heridas permanentes y por supuesto, la muerte.

El estallido de la Gran Guerra del Norte entre Suecia, Rusia, Dinamarca y Sajonia en 1700 significó la creación de una milicia local en Estonia en 1701. Los reclutas de esta nueva unidad procedían de los siervos (había milicias urbanas diferenciadas) y por primera vez se estableció un sistema de reclutamiento sin un consenso con la nobleza local, debilitando así aún más la dominación nobiliaria. Por cada cierta cantidad de tierra habitada, independientemente de ser estatal o privada, 10 siervos eran reclutados ${ }^{29}$.

Otro ámbito en el cual la influencia sueca fue muy importante en la vida cotidiana de los siervos estonios fue la regulación de la protección de la población Sueca y finlandesa del sistema servil. La monarquía sueca solo admitía el sistema servil para la población de origen estonio. Los colonos originarios de Suecia y de Finlandia se establecieron en Estonia desde principios de la Edad Media como campesinos libres, pero la avidez de la nobleza local suponía una amenaza para su independencia. Por tanto el Rey Gustavo Adolfo en 1629 amenazó a la nobleza con revocar todos sus privilegios si obligaban a estos campesinos libres a trabajar en sus haciendas sin compensación alguna ${ }^{30}$. Esta

27. Archivos Históricos de Estonia. TARTU (EHA), 846-2-7847, 'Estnische Bauern als Krieger während der Kämpfe in Livland 1558-1611', 1632.

28. Biblioteca de la universidad de Tartu (UTLIB), F152 A. Archivos personales de Soom, vol. 128, placa de Magnus Gabriel de la Gardie’s, Julio 1657.

29. Archivo de la historia del pueblo estonio en los años de la Gran Guerra del Norte (1700-1721). Valimik dokumente, ed. V. FAINSTEIN et al., nos. 1-47.

30. Archivos Históricos de Estonia. TARTU (EHA), 125-8-9453, 'Eibofolke’, 1629.

Ediciones Universidad de Salamanca / 요 Stud. his., H. ${ }^{a}$ mod., 40, n. 2 (2018), pp. 383-405 
DAVID RAMIRO TROITIÑO, TANEL KERIKMÄE Y ARCHIL CHOCHIA

EL SISTEMA DE SERVIDUMBRE EN ESTONIA: VISIÓN GENERAL E INFLUENCIA SUECA

decisión fue respaldada por el Consejo del Reino reunido en Estocolmo el 30 de Septiembre de 1685, enfatizando su libertad de movimiento una vez que hubieran satisfecho cualquier deuda existente con el señor feudal ${ }^{31}$. La importancia de los campesinos libres suecos, presentes en Estonia hasta finales de la Segunda Guerra Mundial, reside en que cohabitaban con campesinos Estonios y los influenciaban de manera significativa. Los latifundios de la nobleza Estonia situados en la zona de asentamiento del campesinado sueco eran significativamente más pequeños que en otras partes de Estonia y bastante más modestos. Incluso en los latifundios los colonos suecos trabajaban mano a mano con los siervos estonios para los señores feudales con la diferencia de que el trabajo de los suecos tenía que estar remunerado. Por tanto, pese a ser tan solo unos miles de colonos, influenciaron enormemente el noroeste de Estonia y supusieron una mejora de las condiciones serviles en la zona.

Otro de los campos donde la influencia de la monarquía sueca se hizo sentir fue el comercio ya que la legislación real buscaba dinamizar la economía para así incrementar la tasa impositiva y por tanto el montante total recaudado. El proceso, meramente económico, tuvo una gran influencia en la vida de los siervos ya que tocaba de lleno su relación con sus señores feudales. Por ejemplo, una iniciativa de la ciudad de Tartu, segunda en importancia de Estonia, su capital cultural y sede de una universidad fundada por la monarquía sueca, revela la importancia de la corona en las transacciones comerciales en referencia a los siervos. La ciudad pedía permiso al gobernador general para operar un mercado en dos fechas, lunes y sábados, y el gobernador general sueco emitió un edicto al respecto en el cual se constataba la libertad de los siervos de acudir al mercado y vender sus mercancías libremente sin interferencias de sus señores feudales. Además se prohibía explícitamente el monopolio de los terratenientes sobre las ventas de sus siervos, vedando la venta forzada al señor o cualquier otra acción con el objetivo de alejar a los siervos del mercado durante los días señalados ${ }^{32}$. La intervención del estado sueco supuso una significante liberación económica de los siervos en Estonia, ya que por primera vez podían acudir a los mercados a vender sus productos sin necesidad de pasar por su señor feudal como intermediario.

El edicto referente al mercado de Tartu fue ampliado por un memorándum del mismo año en el que el gobernador general extendía el derecho de los siervos de acudir libremente a los mercados de todo el país sin ninguna restricción

31. Archivo provincial de Keila, Pakri rootslaste kaebused Karl XI-le 1684. aastal: muutuste aeg Harju-Madise ja Risti kihelkonnas, 1.41.17.

32. Biblioteca de la Universidad de Tartu (UTLIB), O634 Svensk förvaltning, May, 1630.

Ediciones Universidad de Salamanca / 요 Stud. his., H. ${ }^{a}$ mod., 40, n. 2 (2018), pp. 383-405 
más allá de la satisfacción de deudas e impuestos ${ }^{33}$. De todas formas, dichas regulaciones parece que no fueron respetadas por la nobleza, que de manera ilegal seguía controlando la propiedad de los siervos e impidiendo su libre participación en los mercados, como refleja que el gobernador general volviera a emitir un edicto en el mismo sentido en 1684, 54 años después. En el nuevo edicto se prohibía a la nobleza monopolizar las ventas de sus siervos e impedir que acudieran libremente a los mercados ${ }^{34}$.

El gobierno sueco, buscando una mayor independencia económica de los siervos, promulgó otro edicto en 1698 prohibiendo a los latifundios, en un radio de 6 kilómetros de la ciudad de Tartu, la venta de productos urbanos, como la sal, el hierro, etc. La medida evidentemente pretendía eliminar un monopolio señorial que ralentizaba la economía urbana encareciendo innecesariamente los productos, y haciendo más difícil la independencia económica de los siervos. El edicto también hacía referencia rotunda a la libertad de la que gozaban los siervos para desplazarse a las ciudades y realizar sus compras ${ }^{35}$.

Evidentemente, el objetivo primordial de estos decretos era la protección de la burguesía urbana, mucho más cercana a la corona y más dócil que la levantisca nobleza rural, pero aun así su efecto positivo se extendía a los siervos cuando la legalidad era respetada por los señores feudales, cosa poco común en este caso. Los comerciantes urbanos también tuvieron el apoyo real en otros casos relacionados con los siervos, como en la recaudación de deudas contraídas por los siervos. Como ejemplo, en 1691, el gobernador general conminó a los nobles a ayudar, y no obstaculizar, que Friedrich Arpenbeck, comerciante burgués de Tallin, recaudara las deudas contraídas con él por diversos siervos bajo el control nobiliario ${ }^{36}$.

El otro gran campo de influencia real sobre la vida de los siervos de Estonia fue el acceso de los siervos al sistema judicial. En 1632 se otorgó el derecho a los

33. Archivo pastoral de Tartu, Aruanne reformatsioonipäeva pühitsemise kohta, EAA.1268.1.8.

34. Archivos Históricos de Estonia. TARTU (EHA), 278-1-XVI-37b, f. 45, placa del gobernador general, 19 Febr. 1684. Órdenes similares siguieron: EHA, 5100-1-15, pp. 58-61, placa del gobernador general, 19 Dec. 1695. En el Siglo XVIII se emitieron órdenes parecidas por los gobernadores rusos en 1729, 1733, 1738,1741, 1745, 1747.

35. Archivos Históricos de Estonia. TARTU (EHA), 278-1-XVI-43d, ff. 274-276, La magistratura de Tartu al gobernador E. Soop, 10 Oct. 1698; ibid., ff. 284-285, 'Ex Protocollo Consul: Reg: Civ: Dorpat d: 6. Octubre: Ao. 1698'. En 1726 una placa del gobernador general de Estonia legalizaba la venta de sal y hierro a los siervos por el señor feudal aunque preservaba el derecho de los siervos de comprar en las ciudades otros productos, principalmente ropa. Contradictoriamente, otra placa de 1729 volvía a prohibir la venta de sal por los señores feudales.

36. Archivo histórico de LSHA, 7349-1-45, pp. 159-160, 'Patent vor Fridr. Apenbeck wegen seiner Baurschulden ad Possessores dadl. Güther', 02 March 1691. 
DAVID RAMIRO TROITIÑO, TANEL KERIKMÄE Y ARCHIL CHOCHIA

EL SISTEMA DE SERVIDUMBRE EN ESTONIA: VISIÓN GENERAL E INFLUENCIA SUECA

siervos de acudir directamente a los tribunales reales en el caso de conflicto con los funcionarios reales de los latifundios públicos o arrendatarios de latifundios privados, pero en ningún caso estaban incluidos los conflictos con el propio señor feudal ${ }^{37}$. Aunque en 1680 las quejas de los siervos en los tribunales estatales eran investigadas seriamente e incluso incluían contenciosos entre siervos y señores feudales de manera excepcional, incrementando así la influencia judicial de la corona sobre la relación entre la nobleza y sus siervos, anteriormente área de influencia exclusiva nobiliaria. De todas formas, la efectividad de la legalidad estatal se enfrentaba a la poca colaboración de la nobleza, habituada a un control total sobre sus siervos. Por ejemplo, en 1644, el gobernador general sueco, Erik Eriksson Ryning, se encontraba de visita en el latifundio Adsel, cuando un siervo, Johan Branck, le hizo llegar directamente una queja formal sobre el arrendatario de la propiedad. El gobernador general mandó paralizar el contrato en cuestión hasta que se realizaran las pertinentes indagaciones para esclarecer el caso, tras lo cual siguió su viaje. Nada más abandonar la propiedad, el arrendatario llegó incluso a amenazar con la muerte al siervo por su descaro al saltarse el uso tradicional del latifundio donde su palabra era ley ${ }^{38}$, poniendo de manifiesto la limitación del poder real y la impunidad de la nobleza acostumbrada a actuar libremente en su relación con los siervos.

Otra queja transmitida por un siervo del latifundio Koitjärw al gobernador general en 1693 fue el primer caso en el que se pidieron explicaciones a un señor feudal, aunque el caso no fuera más allá, por lo que el siervo acudió directamente al Rey en Estocolmo (algo inusual en la época). El Rey ordenó directamente al gobernador general que prestase la debida atención al caso. Finalmente, el tribunal comarcal sentenció a favor del siervo, que recuperó legalmente sus propiedades ilegalmente confiscadas por el noble denunciado. Pese a lo cual, el terrateniente se resistió a cumplir la condena, poniendo en evidencia la debilidad del estado para interferir en las relaciones siervo -señor, aunque finalmente fue forzado a respetar la sentencia bajo amenaza de pena capital ${ }^{39}$.

En el mismo sentido, el señor feudal de Attel en 1695 se resistió a acatar una sentencia de los tribunales que le condenaba a la devolución de grano a sus siervos por incautación indebida. Ante la negativa del noble en cuestión de aceptar la sentencia ya que era contraria a sus intereses, el gobernador general incluso llegó

37. Archivo histórico de LSHA, 7402-1-11), f. 13v. Manuscrito, Riga, Letonia, 1644.

38. Archivos Históricos de Estonia. TARTU (EHA), 278-1-XVI-3a, f. 5, Investigación sobre las quejas de los siervos de Adsel, 1645-1646.

39. Archivos Históricos de Estonia. TARTU (EHA), 1-2-133, f. 14v, El gobernador general de Estonia al tribunal comarcal de Harrien. 31 Jan. 1695; EHA 861-1-1887, ff. 17-63v, sentencia sobre el caso del siervo del tribunal comarcal de Harrien, 27 Sept. 1694-10 Febr. 1696.

Ediciones Universidad de Salamanca / 요 Stud. his., H. ${ }^{a}$ mod., 40, n. 2 (2018), pp. 383-405 
a enviar tropas al latifundio para mantener bajo arresto domiciliario al señor feudal hasta que el grano fuera devuelto a sus legítimos propietarios. Finalmente, el barón Otto Johann von Meyendorff-Uxkül satisfizo su deuda con los siervos ${ }^{40}$.

En un último esfuerzo para reafirmar la supremacía real en las relaciones con los siervos de Estonia, en 1695, el gobernador general, en la reunión oficial del estado con la nobleza, hizo clara referencia a los excesos de los nobles en lo concerniente a las numerosas quejas recibidas de siervos por exceso de violencia corporal, instando a los nobles a tratar de manera comedida a sus siervos, ya que también eran súbditos reales ${ }^{41}$.

Finalmente, la última área de influencia sueca, y sin duda, la más efectiva en la influencia de la monarquía sobre la vida de los siervos, está relacionada con la educación. Ya en 1601 el príncipe Carlos conminaba a la nobleza de Estonia a facilitar la educación de los hijos de sus siervos y permitir que eligieran libremente su futuro, ya que no se trataba de esclavos ${ }^{42}$. La educación se concebía como una herramienta en la emancipación de los hijos de los siervos, ya que con los conocimientos adquiridos, unidos a la libertad para desplazarse y escoger profesión, el sistema servil desaparecería paulatinamente. Evidentemente la nobleza local estuvo en contra de la instauración del sistema educativo propugnado por Suecia por dos motivos, su potencial emancipador y porque los costes económicos del sistema debían de ser asumidos directamente por la nobleza rural. En 1690, gracias a la presión real, la nobleza finalmente aceptó el sistema escolar propuesto y se responsabilizó de la construcción de escuelas rurales, con ventanas, en sus dominios. Pese a que aún se oponían a la contratación (y pago) de un maestro para cada escuela ya que en su opinión el párroco era suficiente para instruir a los siervos ${ }^{43}$.

La gran guerra del Norte afectó enormemente al territorio y al sistema educativo impuesto por la corona sueca provocando graves disfunciones en el mismo, pero la autoridad Rusa reinstauró el sistema, incluyendo a la figura independiente del maestro rural. Finalmente en 1765 se legisló estableciendo la obligatoriedad de que todos los latifundios a partir de una extensión determinada de tierra, debían de contar con una escuela y un maestro pagados por el señor para los hijos de sus siervos ${ }^{44}$. Por tanto, el sistema se consolidó durante el

40. Archivo histórico de LSHA, 7349-2-34, pp. 188-191, 1695.

41. Archivo histórico de HA, 1-2-133, f. 201, 1695.

42. Archivos Históricos de Estonia. TARTU (EHA), 1-2-133, f. 58v, 1601.

43. Archivo histórico de UTLIB, Est B-197,1690.

44. P.-M. HAHN, P.-M: Fürstliche Territorialhoheit und lokale Adelsgewalt. Die herrschaftliche Durchdringung des ländlichen. Raumes zwischen Elbe und Aller (1300-1700), Berlin/ New York 1989, p. 508. 
DAVID RAMIRO TROITIÑO, TANEL KERIKMÄE Y ARCHIL CHOCHIA

EL SISTEMA DE SERVIDUMBRE EN ESTONIA: VISIÓN GENERAL E INFLUENCIA SUECA

periodo de ocupación Zarista, pero evidentemente era consecuencia del modelo desarrollado por los suecos.

Otros aspectos importantes de la vida de los siervos no fueron influenciados por la larga ocupación sueca, como la mendicidad o la obligación de los señores feudales de mantener a sus siervos o a los pobres instalados en sus propiedades. En cuanto a la libertad de matrimonio, los señores feudales (en teoría) no tenían derecho legal sobre las novias campesinas en lo referente a sus matrimonios y a su capacidad de instalarse junto a su nuevo esposo en otra propiedad señorial. Aunque una serie de edictos a principios del siglo XVIII hacen referencia explícita a la prohibición a señores feudales o arrendatarios de latifundios públicos a impedir bodas entre siervos de distintas propiedades ${ }^{45}$. Durante la dominación sueca esta práctica estaba completamente prohibida, pero la necesidad de legislar al respecto por parte del gobernador ruso, pone de relevancia el retroceso sufrido por los campesinos estonios durante la inestabilidad de la gran guerra del Norte, una época usaba por la nobleza para revertir las medidas suecas de protección de los siervos.

\section{CONCLUSIONES}

La principal herencia del periodo sueco fue el sistema educativo y el funcionamiento de la iglesia sueca, que siguió operando de manera normal sin graves interrupciones pese la gran guerra del Norte y a la ocupación rusa ${ }^{46}$. Los sacerdotes suecos, siguiendo las enseñanzas de Lutero, fundaron numerosas escuelas rurales para que los campesinos pudieran leer por si mismos las sagradas escrituras. La red de escuelas rurales fue reglamentada por la monarquía y se estableció un sistema de pago público para el profesorado e incluso se creó un seminario donde los profesores eran preparados para realizar sus funciones. El nivel de alfabetización de la población servil era muy alto para la época ya que alrededor del $50 \%$ de la población podía leer en el siglo XVIII, y los siervos no eran ajenos a esta tendencia ya que una gran parte aprendía a leer en sus propias casas. La población servil también era bilingüe en su mayoría ${ }^{47}$, ya que el alemán de la aristocracia era comúnmente aprendido por los siervos que también conservaron su propio idioma, el estonio, enfatizando así el

45. Archivo histórico de UTLIB, Est A-279, Livländische Gouvernements-RegierungsPatente, 02 Jan. 1716, 08 Aug. 1733, 30 March 1756.

46. En el acuerdo entre la nobleza Estonia y el Zar para la incorporación del país al imperio ruso se estableció la prohibición de proselitismo de la Iglesia Ortodoxa rusa en Estonia.

47. Viitso, Tiit-Rein: «Rise and development of the Estonian language.» Estonian Language, Tallin, 2003, pp. 130-230. 
DAVID RAMIRO TROITIÑO, TANEL KERIKMÄE Y ARCHIL CHOCHIA

EL SISTEMA DE SERVIDUMBRE EN ESTONIA: VISIÓN GENERAL E INFLUENCIA SUECA

carácter nacional de la dominación germana. Durante el periodo ruso también se mantuvo el sistema de valoración de la tierra impuesto por los suecos, así como los impuestos a pagar por los siervos, manteniendo ciertos aspectos de la relación directa entre la monarquía y los siervos creada por Suecia. Pese a lo cual, el fin de la dominación sueca trajo una reducción considerable de los derechos de los siervos, ya que el Zar ruso necesitaba la colaboración activa de la nobleza local para controlar de manera efectiva el territorio. Esto se tradujo en la confirmación de los privilegios de la nobleza y la cancelación de la mayoría de las reformas suecas que ponían en entredicho el poder absoluto de los nobles frente a sus siervos.

Aunque la existencia de latifundios públicos decreció durante la ocupación rusa debido a las generosas donaciones zaristas a la nobleza, siguió existiendo de manera relevante. Los siervos de estas propiedades públicas siguieron disfrutando de la anterior legalidad instaurada por los suecos y evidentemente influenciaron con sus relaciones con otros siervos, el desarrollo de la servidumbre en Estonia.

En definitiva, la ocupación sueca mitigó el poder de la nobleza local sobre sus siervos al introducir numerosas reformas en las cuales el estado asumía funciones previamente privadas con una posición bastante más amable hacia los siervos, en definitiva súbditos reales y base del sistema económico y social imperante. El colapso del imperio sueco tras la gran guerra del Norte y la ocupación rusa supuso una importante regresión de las condiciones de los siervos y un importante resurgir del poder absoluto de la nobleza local, lo que evidentemente significó la creación de un imaginario local sobre la bondad de la ocupación sueca. Aún hoy en día la mayoría de la población estonia tiene un concepto muy positivo del periodo sueco y en las escuelas se estudia como el periodo dorado o los buenos tiempos suecos, cuando las condiciones de vida de los siervos estonios mejoraron considerablemente, aunque solo fuera de manera temporal para caer en una regresión brutal posteriormente.

\section{FUENTES PRIMARIAS}

Archivo local de Virve. Folvark, pan ipoddannyj. Agrarnye otnosheniya v polskikh vladeniyakh na territorii Juzhnoi Estonii vkontse XVI-nachale XVII veka, 199-133, ä. $58 \ddot{\mathrm{u}}, 1561$.

Archivo pastoral de Tartu, Aruanne reformatsioonipäeva pühitsemise kohta, EAA.1268.1.8. Archivos Históricos de Estonia. TARTU (EHA):

601-6-2937, 1601.

1-2-133, f. 58v, 1601.

125-8-9453, 'Eibofolke’, 1629.

Ediciones Universidad de Salamanca / @®@@ Stud. his., H. ${ }^{a}$ mod., 40, n. 2 (2018), pp. 383-405 
DAVID RAMIRO TROITIÑO, TANEL KERIKMÄE Y ARCHIL CHOCHIA

EL SISTEMA DE SERVIDUMBRE EN ESTONIA: VISIÓN GENERAL E INFLUENCIA SUECA

846-2-7847, 'Estnische Bauern als Krieger während der Kämpfe in Livland 1558-1611', 1632.

278-1-XVI-3a, f. 5, Investigación sobre las quejas de los siervos de Adsel, 1645-1646.

861-1-3390, 'Inquisitio wegen eines übel verwundeten Baurens Ebarte Mickß und eines auff Rasick im Gefangnuß gestorbenen frey Kerlß Bents’, 1672.

1-1-112, ff. 44-45v, Hulpar Hanß and Putnik Martt al gobernador de Estonia Bengt Horn, 22 Febr. 1672.

1-2-133, f. 14v, El gobernador general de Estonia al tribunal comarcal de Harrien. 31 Jan. 1695; EHA 861-1-1887, ff. 17-63v, sentencia sobre el caso del siervo del tribunal comarcal de Harrien, 27 Sept. 1694-10 Febr. 1696.

278-1-XVI-37b, f. 45, placa del gobernador general, 19 Febr. 1684. Órdenes similares siguieron: EHA, 5100-1-15, pp. 58-61, placa del gobernador general, 19 Dec. 1695. En el Siglo XVIII se emitieron órdenes parecidas por los gobernadores rusos en $1729,1733,1738,1741,1745,1747$.

278-1-XVI-43d, ff. 274-276, La magistratura de Tartu al gobernador E. Soop, 10 Oct. 1698; ibid., ff. 284-285, 'Ex Protocollo Consul: Reg: Civ: Dorpat d: 6. Octubre: Ao. 1698'.

Archivo Historico del EELK. Kirjavahetus Bielefeld-Stieghorsti Gustav Adolfi kogudusele kuulunud oreli vahendamisest Avinurme kogudusele.

Archivo histórico de LSHA:

7363-5-28, p. 5, 'Ordnung, wonach die pauren alhie in Liefland sollen stazei geben', 12 Sept. 1622.

7402-1-11), f. 13v. Manuscrito, Riga, Letonia, 1644.

7349-1-45, pp. 159-160, 'Patent vor Fridr. Apenbeck wegen seiner Baurschulden ad Possessores dadl. Güther', 02 March 1691.

7349-2-34, pp. 188-191, 1695.

Archivo Histórico de la ciudad de Tallin, Actio Appellatoria in causa Claus Habben und Christoph Brehmers, 1686-1687. TLA.230.3.879.

Archivo de la historia del pueblo estonio en los años de la Gran Guerra del Norte (17001721). Valimik dokumente, ed. V. FAINSTEIN et al., nos. 1-47.

Archivo provincial de Keila, Pakri rootslaste kaebused Karl XI-le 1684. aastal: muutuste aeg Harju-Madise ja Risti kihelkonnas, 1.41.17.

Archivo histórico de UTLIB:

Est B-197,1690.

Est A-279, Livländische Gouvernements-Regierungs-Patente, 02 Jan. 1716, 08 Aug. 1733, 30 March 1756.

Biblioteca de la Universidad de Tartu (UTLIB), O634 Svensk förvaltning, May, 1630.

Biblioteca de la universidad de Tartu (UTLIB), F152 A. Archivos personales de Soom, vol. 128, placa de Magnus Gabriel de la Gardie’s, Julio 1657.

Ediciones Universidad de Salamanca / @®®@ Stud. his., H. ${ }^{a}$ mod., 40, n. 2 (2018), pp. 383-405 
DAVID RAMIRO TROITIÑO, TANEL KERIKMÄE Y ARCHIL CHOCHIA

EL SISTEMA DE SERVIDUMBRE EN ESTONIA: VISIÓN GENERAL E INFLUENCIA SUECA

\section{BIBLIOGRAFÍA}

Anatol, Lieven: The Baltic revolution: Estonia, Latvia, Lithuania and the path to independence. London, Yale University Press, 1994.

Braghiroli, Stefano, y Carta, Caterina: «An index of friendliness toward Russia: An analysis of the member states and Member of the European Parliament's positions.» Pan-European Institute Electronic Publication of 15.09, 2009.

de la Guardia, Ricardo, y Pérez Sánchez, Guillermo: Los paises de la antigua Europa del Este y España ante la ampliación de la Unión Europea. Valladolid. Instituto de estudios europeos, 2001.

Evas, Tatjana: «General Frameworks.» The Law of the Baltic States. Berlin, Springer International Publishing, 2017. 3-40.

Karonen, Petri: «Coping with Peace after a Debacle: the Crisis of the Transition to Peace in Sweden after the Great Northern War (1700-1721).» Scandinavian Journal of History 33.3, 2008, pp. 203-225.

Kerikmäe, Tanel: Estonia in the European legal system: protection of the rule of law through constitutional dialogue. Tallin, Tallinn University, 2009.

Kerikmäe, Tanel, y Chochia, Archil: Political and Legal Perspectives of the EU Eastern Partnership Policy. Berlin, Springer, 2016.

Laur, Mati: History of Estonia. Tallin, Avita, 2000.

Mol, Johannes, Militzer, A. Klaus y Nicholson, Helen J: The Military Orders and the Reformation: Choices, State Building, and the Weight of Tradition. Hilversum, Uitgeverij Verloren, 2006.

Olsson, Mats: «Manorial economy and corvée labour in southern Sweden 1650-1850.» The economic history review 59.3, 2006, pp. 481-497.

Hahn, P.-M.: Fürstliche Territorialhoheit und lokale Adelsgewalt. Die herrschaftliche Durchdringung des ländlichen. Raumes zwischen Elbe und Aller (1300-1700), Berlin/ New York 1989, p. 508.

Pérez, Juan Carlos, y Ramiro Troitiño, David: «El idioma estonio y la influencia geopolítica sobre su desarrollo.» Onomázein 33, 2016, pp. 189-200.

Runciman, Steven: The Crusades and the Military Orders: expanding the frontiers of medieval Latin Christianity. Tallin, Vol. 1. Central European University Press, 2001.

Sillaste, Kyllike: «Conquest and survival: An outline of Estonian history.» World Affairs, 157.3, 1995, pp. 119-123.

Singleton, Fred, y Upton, Anthony F: A short history of Finland. Londres, Cambridge University Press, 1998.

Troitino, David Ramiro: European Integration: Building Europe. New York, Nova Science Publishers, 2013.

Vernygora, Vlad: «Discovering the Baltics? Think Tallinn! Perspectives for New Zealand in the Baltic States.» Tallin, 2011.

Viitso, Tiit-Rein: «Rise and development of the Estonian language.» Estonian Language, Tallin, Linguistica Uralica. Supplementary series. Volume 1, 2003.

Ediciones Universidad de Salamanca / @®@@ Stud. his., H. ${ }^{a}$ mod., 40, n. 2 (2018), pp. 383-405 